OPEN ACCESS

Edited by:

Andreas Martin Grabrucker, University of Limerick, Ireland

Reviewed by: Rodney Johnson,

University of Illinois at Urbana-Champaign, United States Abhishek Asthana, Case Western Reserve University, United States

*Correspondence:

Kil S. Lee

kslee@unifesp.br

Received: 26 January 2017 Accepted: 28 April 2017 Published: 17 May 2017

Citation:

Pino JMV, da Luz MHM, Antunes HKM, Giampá SQdC, Martins VR and Lee KS (2017) Iron-Restricted Diet Affects Brain Ferritin Levels, Dopamine Metabolism and Cellular Prion Protein in a Region-Specific Manner.

Front. Mol. Neurosci. 10:145. doi: 10.3389/fnmol.2017.00145

\section{Iron-Restricted Diet Affects Brain Ferritin Levels, Dopamine Metabolism and Cellular Prion Protein in a Region-Specific Manner}

\author{
Jessica M. V. Pino ${ }^{1}$, Marcio H. M. da Luz', Hanna K. M. Antunes ${ }^{2,3}$, \\ Sara Q. de Campos Giampá ${ }^{3}$, Vilma R. Martins ${ }^{4}$ and Kil S. Lee ${ }^{1 *}$ \\ 1 Departamento de Bioquímica, Universidade Federal de São Paulo, São Paulo, Brazil, ${ }^{2}$ Departamento de Psicobiologia, \\ Universidade Federal de São Paulo, São Paulo, Brazil, ${ }^{3}$ Departamento de Biociências, Universidade Federal de São Paulo, \\ São Paulo, Brazil, ${ }^{4}$ AC Camargo Cancer Center, São Paulo, Brazil
}

Iron is an essential micronutrient for several physiological functions, including the regulation of dopaminergic neurotransmission. On the other hand, both iron, and dopamine can affect the folding and aggregation of proteins related with neurodegenerative diseases, such as cellular prion protein $\left(\mathrm{PrP}^{\mathrm{C}}\right)$ and $\alpha$-synuclein, suggesting that deregulation of iron homeostasis and the consequential disturbance of dopamine metabolism can be a risk factor for conformational diseases. These proteins, in turn, are known to participate in the regulation of iron and dopamine metabolism. In this study, we evaluated the effects of dietary iron restriction on brain ferritin levels, dopamine metabolism, and the expression levels of $\mathrm{PrPC}^{\mathrm{C}}$ and $\alpha$-synuclein. To achieve this goal, C57BL/6 mice were fed with iron restricted diet (IR) or with normal diet (CTL) for 1 month. IR reduced iron and ferritin levels in liver. Ferritin reduction was also observed in the hippocampus. However, in the striatum of IR group, ferritin level was increased, suggesting that under iron-deficient condition, each brain area might acquire distinct capacity to store iron. Increased lipid peroxidation was observed only in hippocampus of IR group, where ferritin level was reduced. IR also generated discrete results regarding dopamine metabolism of distinct brain regions: in striatum, the level of dopamine metabolites (DOPAC and HVA) was reduced; in prefrontal cortex, only HVA was increased along with the enhanced MAO-A activity; in hippocampus, no alterations were observed. $\mathrm{PrP}^{\mathrm{C}}$ levels were increased only in the striatum of IR group, where ferritin level was also increased. $\mathrm{PrP}^{\mathrm{C}}$ is known to play roles in iron uptake. Thus, the increase of $\mathrm{PrP}^{\mathrm{C}}$ in striatum of IR group might be related to the increased ferritin level. $\alpha$-synuclein was not altered in any regions. Abnormal accumulation of ferritin, increased MAO-A activity or lipid peroxidation are molecular features observed in several neurological disorders. Our findings show that nutritional iron deficiency produces these molecular alterations in a region-specific manner and provide new insight into the variety of molecular pathways that can lead to distinct neurological symptoms upon iron deficiency. Thus, adequate iron supplementation is essential for brain health and prevention of neurological diseases.

Keywords: iron deficiency, dopamine, ferritin, prion protein, $\alpha$-synuclein 


\section{INTRODUCTION}

Iron is an important micronutrient that participates in several vital cellular functions such as oxygen transport and cellular respiration. Moreover, iron is a cofactor for numerous enzymes. Despite its importance, free iron is known to cause oxidative damages in cellular environment due to its ability to generate free radicals through Fenton reaction (Zecca et al., 2004; Belaidi and Bush, 2015). Indeed, abnormal accumulation of iron in brain has been pointed out as one of the factors that accelerate the aggregation of proteins associated with neurodegenerative diseases, such as cellular prion protein $\left(\mathrm{PrP}^{\mathrm{C}}\right)$ and $\alpha$-synuclein (Golts et al., 2002; Das et al., 2010). Moreover, iron can bind to protein aggregates and enhance their toxicity by attributing redox activity to these aggregates (Liu et al., 2011).

On the other hand, iron deficiency can turn out the aerobic respiration inefficient leading to reduced energy production and accumulation of reactive oxygen species, which can culminate into mitochondrial dysfunction (Masini et al., 1994; Walter et al., 2002). Iron deficiency can also cause deregulation of monoaminergic system. Inhibition of iron uptake into dopaminergic neurons not only caused mitochondrial damage, but also reduced dopamine levels and evoked abnormal activity of dopamine receptors (Matak et al., 2016). Several studies have also reported that nutritional iron deficiency alters dopaminergic neurotransmission, increasing the concentration of extracellular dopamine and reducing the activity of dopamine transporter (DAT) and D2 receptor in striatum (Youdim et al., 1989; Beard et al., 1994; Bianco et al., 2008; Unger et al., 2014). Reduced DAT expression has been also reported in the ventral midbrain (Bianco et al., 2008). These alterations appear to contribute to the memory impairment, attention deficiency and learning problems frequently observed in iron-deficient population (Youdim et al., 1989; Asanuma et al., 2003; Radlowski and Johnson, 2013; Gupta, 2016; Scott and Murray-Kolb, 2016). However, how nutritional iron deficiency affects the brain iron metabolism, particularly in dopaminergic regions, is poorly understood. Brain appears to have a greater tendency to retain iron and resist to nutritional iron deficiency due to the slow exchange of iron out of brain (Youdim et al., 1989; Bradbury, 1997). However, a few studies have demonstrated that dietary iron restriction reduces the iron levels of ventral midbrain and striatum in young rats (Bianco et al., 2008; Unger et al., 2014), while others claimed that iron levels of striatum were not altered after similar treatment (Erikson et al., 1997). Thus, the effects of dietary iron on the iron metabolism in dopaminergic neurons need to be better investigated.

Dopamine is a neurotransmitter that participates in the regulation of motor coordination, responses to rewarding experiences, attention and mood (Russo and Nestler, 2013; Bissonette and Roesch, 2016). At the same time, dopamine can be neurotoxic, being readily oxidized by non-enzymatic reactions, which generate reactive molecules, such as dopamine quinone (Lotharius and Brundin, 2002; Asanuma et al., 2003). Oxidative

Abbreviations: $\operatorname{PrP}^{\mathrm{C}}$, Cellular Prion Protein; IR, iron restricted diet; CTL, control diet; TH, tyrosine hydroxylase; DAT, dopamine transporter; DOPAC, 3,4Dihydroxyphenylacetic acid; HVA, homovanillic acid; MAO, Monoamine oxidase. dopamine metabolites are known to promote the aggregation of $\alpha$-synuclein into non-ordered toxic oligomers, and these molecular alterations are closely associated with pathogenesis of Parkinson's disease (Lotharius and Brundin, 2002; Yamakawa et al., 2010). Dopamine can also induce the aggregation of $\operatorname{PrP}^{\mathrm{C}}$, another aggregation-prone protein associated with transmissible spongiform encephalopathies, a fatal neurodegenerative disease (da Luz et al., 2015).

Altogether, these previous findings suggest that the aggregation of $\alpha$-synuclein and $\operatorname{PrP}^{\mathrm{C}}$ can be promoted either by iron or by dopamine, and both excess and deficiency of iron can be a risk factor for conformational diseases through distinct molecular mechanisms. It is possible that the distinct subcellular localization of the proteins and the site of iron and/or dopamine accumulation contribute to the specificity of pathogenic pathways. Thus, in this study, we evaluated how dietary iron restriction influences brain ferritin (a main iron storage protein) and dopamine metabolism in striatum, hippocampus and prefrontal cortex, three regions that receive afferents from midbrain dopaminergic neurons (Yetnikoff et al., 2014) and investigated how altered iron and dopamine metabolism can affect the expression level and solubility of $\operatorname{PrP}^{\mathrm{C}}$, a protein that is anchored to the outer leaflet of the plasma membrane. As mentioned above, dietary iron restriction is known to increase the concentration of extracellular dopamine. Since the accumulation of $\alpha$-synuclein occur due to the intracellular dopamine, in order to check the specificity of the iron restriction effects on proteins of distinct subcellular comportments, we also analyzed the level of $\alpha$-synuclein, which is a cytosolic protein.

\section{MATERIALS AND METHODS}

\section{Dietary Iron restriction}

Three-month-old male C57BL/6 mice were used in this study. The animals were randomly distributed into two groups: control group (CTL) that was fed with normal diet containing $45 \mathrm{ppm}$ of iron (Research Diets, USA, cat \# D100012G) and IR group that was fed with iron restricted diet containing approximately 3 ppm of iron (Research Diets, USA, cat \# D0372501N) for 4 weeks. This protocol was chosen based on the previous studies (Youdim et al., 1989; Beard et al., 1994; Bianco et al., 2008; Kamei et al., 2013; Unger et al., 2014). During the experimental period, the animals were housed in a temperature-controlled room at $23 \pm 2^{\circ} \mathrm{C}$ with a $12 / 12$-h light/dark cycle, and water and food were supplied ad libitum. The food was removed $2 \mathrm{~h}$ before euthanasia. All experimental procedures were approved by the Research Ethics Committee of UNIFESP (CEUA N 9806251113). All experimental procedures complied with the Guide for the Care and Use of Laboratory Animals (National Research Council, NIH Publication No. 85-23, 2011 revision). This study does not contain any individual persons data. The datasets used and/or analyzed during the current study available from the corresponding author on reasonable request.

\section{Iron Status}

After blood clotting, samples were centrifuged at $1,100 \times \mathrm{g}$ for $10 \mathrm{~min}$ and serum was collected. For liver, small peripheral piece of the organ was dissected to avoid harvesting main veins and 
the piece were extensively rinsed in PBS prior to lysis. Liver, striatum, prefrontal cortex and hippocampus were homogenized in phosphate buffered saline (PBS). Total amount of iron in serum and in liver was measured using Ferene $S$ provided in the commercially available colorimetric assay kit (BioVision, USA, cat\# K390-100). Buffers provided in this kit dissociate iron from iron carrier proteins, and after reduction of ferric iron, total iron is detected as ferrous form. Ferritin and transferrin receptor were quantified using enzyme linked immunosorbent assay kits: Ferritin ELISA kit (Abnova, USA, cat \# KA1941) and Transferrin receptor ELISA kit (Mybiosource, USA, cat \# MBS026588). All experiments were performed according to the instructions of the manufacturers.

\section{Lipid Peroxidation}

Striatum, prefrontal cortex and hippocampus were homogenized in RIPA buffer (Tris $50 \mathrm{mM} \mathrm{pH} \mathrm{8,} \mathrm{NaCl} 150 \mathrm{mM}$, SDS 1\%, tritonx100 1\%, Sodium deoxycholate $0.5 \%)$. After the centrifugation of homogenates at $1,600 \times \mathrm{g}$ for $10 \mathrm{~min}$, post-nuclear supernatant was collected and the concentration of malondialdehyde was determined using fluorimetric TBARS assay kit (Cayman, USA, cat \# 10009055).

\section{Dopamine and Its Metabolites}

Levels of dopamine and its metabolites were determined using HPLC-ECD system composed of ECD-700 detector, ECD-700 pump and ATC-700 temperature controller (Eicom, Japan). Striatum, prefrontal cortex and hippocampus were homogenized in $0.2 \mathrm{M} \mathrm{HClO}_{4}$ and centrifuged at $20,000 \times \mathrm{g}$ for $15 \mathrm{~min}$. Supernatant $\mathrm{pH}$ was adjusted to 3 using sodium acetate $2 \mathrm{M}$, and then filtered through $0.22 \mu \mathrm{m}$ PVDF membrane. Samples $(10 \mu \mathrm{l})$ were injected every $25 \mathrm{~min}$ onto SC-3ODS HPLC column coupled to pre-column packed with AC-ODS, using the auto sampler 700 (Eicom, Japan). The isocratic mobile phase consisted of citric acid $42 \mathrm{mM}$, sodium acetate $38 \mathrm{mM}$, EDTA$\mathrm{Na}_{2} 13 \mu \mathrm{M}$ and sodium octanesulfonate $1 \mathrm{mM}$. The flow rate was $340 \mu \mathrm{l} / \mathrm{min}$. The analytes were detected using graphite working electrode $\mathrm{WE}-3 \mathrm{G}$ set at $+750 \mathrm{mV}$ vs. $\mathrm{Ag} / \mathrm{AgCl}$ reference electrode.

\section{Monoamine Oxidase (MAO) activity}

Striatum and prefrontal cortex were homogenized in $50 \mu \mathrm{l}$ of MAO buffer provided in Monoamine Oxidase Activity Fluorometric Assay Kit (BioVision, USA, Cat\# K795-100) and supernatant was recovered after the centrifugation at $1,000 \times \mathrm{g}$ for $10 \mathrm{~min}$. After combining samples, substrate and fluorescent probe for $\mathrm{H}_{2} \mathrm{O}_{2}$ provided in the kit, the fluorescence was measured every $1 \mathrm{~min}$ during an hour. MAO-A activity was determined using selective MAO-B inhibitor selegilin, also provided in the kit.

\section{Western Blot}

Tissues were homogenized in lysis buffer [Tris $50 \mathrm{mM} \mathrm{pH} \mathrm{8,} \mathrm{NaCl}$ $150 \mathrm{mM}$, EDTA $10 \mathrm{mM}$, triton-x100 1\%, Sodium deoxycholate $0.5 \%$, cOmplete ${ }^{\mathrm{TM}}$ Protease Inhibitor Cocktail (Roche, Brazil), Phosphatase Inhibitor Cocktail set II (Millipore, Brazil)] and post-nuclear supernatant was collected after the centrifugation at 3,000 $\times \mathrm{g}$ for $5 \mathrm{~min}$. Following SDS-PAGE, proteins were transferred to PVDF membrane and the protein of interest was detected using primary antibodies: SAF32 for $\mathrm{PrP}^{\mathrm{C}}$ (Cayman Chemical, USA, Cat \#189720); anti- $\alpha$-synuclein (Cell Signaling Technology, USA, Cat \# 2642); anti- tyrosine hydroxylase (TH) (Cell Signaling Technology, USA, Cat \# 27925); anti- DAT (EDM Millipore, USA, Cat \# MAB369); anti- GAPDH (Cell Signaling Technology, USA, Cat \#2118). The signals were revealed with HRP-conjugated secondary antibodies and Luminata ${ }^{\mathrm{TM}}$ Forte Western HRP Substrate (Millipore, USA, Cat\#WBLUF0500). Digital images of membranes were acquired using Alliance Mini gel documentation system (UVITEC, UK). Band intensity was quantified using software UVIband (UVITEC, UK). The intensity of the protein of interest was normalized with the GAPDH band and data were presented as percentage of mean of control group.

\section{Ultracentrifugation}

Post-nuclear supernatant prepared in PBS were incubated with $1 \%$ sarkosyl for $10 \mathrm{~min}$ on ice and centrifuged at 30,000 r.p.m. for $3 \mathrm{~h}$ at $4^{\circ} \mathrm{C}$ using Optima L-100 Ultracentrifuge and Sw55TI rotor (Beckman Coulter, Inc, USA). After collecting soluble fractions (supernatant), insoluble fractions (pellets) were rinsed with PBS and dissolved in $4 \mathrm{x}$ sample buffer (8\% SDS, Tris $\mathrm{HCl} 250 \mathrm{mM}$, $\mathrm{pH} 6.8,40 \%$ Glycerol, $0.08 \mathrm{mg} / \mathrm{ml}$ bromophenol blue and $1.4 \mathrm{M}$ $\beta$-mercaptoetanol) with vigorous vortexing and sonication. One twentieth of the supernatant volume was used to dissolve the pellets.

\section{Data Analysis}

For each experiment, 3-10 independent biological samples per group were analyzed depending on the availability of samples. All individual observations were presented in scatter plots. Data were analyzed using non-parametric Mann-Whitney $U$-tests and groups were considered significantly different when the $\mathrm{p}$ value was lower than 0.05 . All statistical analyses presented in this study were performed including potential outliers. However, the exclusion of the potential outliers did not affect the significance level of the results (data not shown).

\section{RESULTS}

\section{Body Weight and Iron Status}

Animals fed with iron-depleted chow (IR) for 30 days gained $2.5 \pm 0.9 \mathrm{~g}$ (mean $\pm \mathrm{SD}, n=10$ ) throughout the experimental period. This weight gain was not significantly different from that observed in control group (CTL): $3.0 \pm 1.3 \mathrm{~g}$ (mean $\pm \mathrm{SD}$, $n=10$ ). These results were replicated in further independent experiments.

IR group presented reduced iron levels in liver (Figure 1A), and reduced ferritin in serum and liver (Figure 1C) compared to CTL group, but the concentration of serum iron and transferrin receptor were not altered (Figures 1A,B). These data suggest that 30 days of dietary iron restriction caused mild iron deficiency.

Ferritin level was also reduced in the hippocampus of IR group compared to CTL, but in the striatum, ferritin level was increased with dietary iron restriction (Figure 1C). In prefrontal 


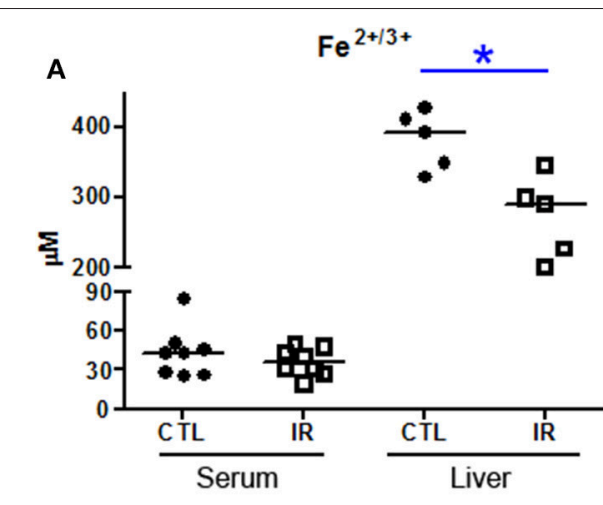

B

Trf-R

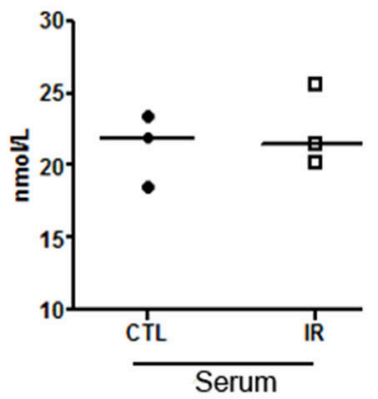

Trf-R

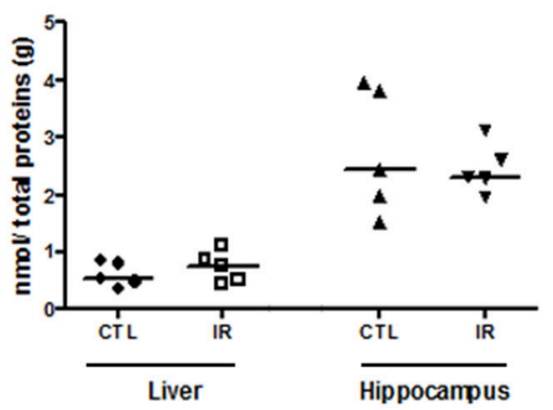

C
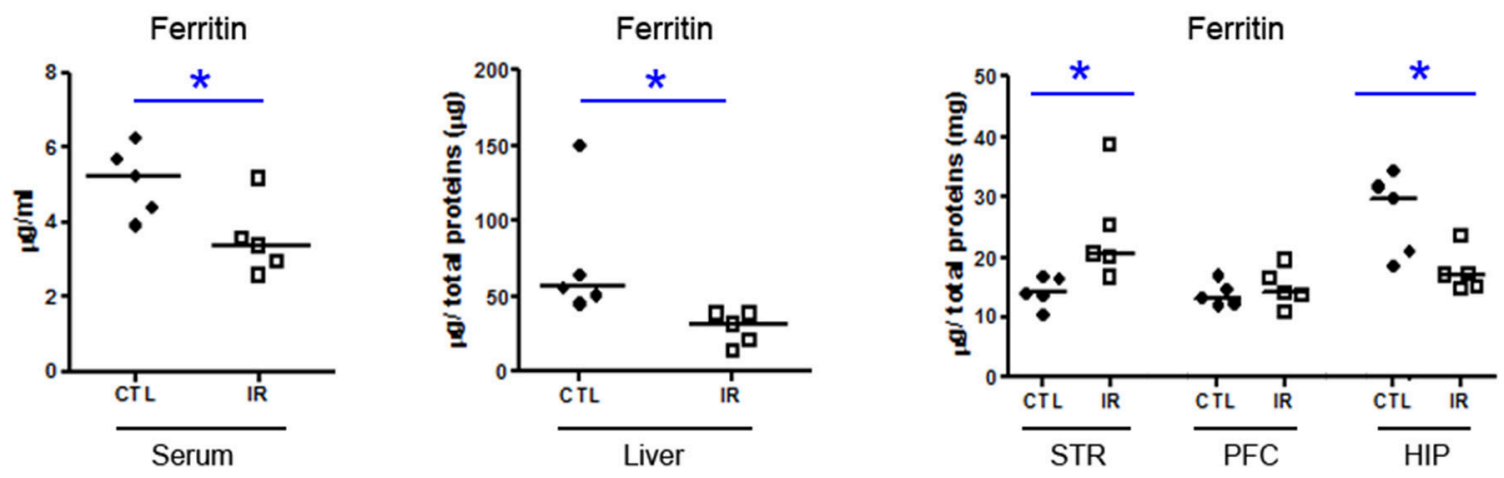

FIGURE 1 | Iron Metabolism. (A) Total amount of $\mathrm{Fe}^{2+/ 3+}$ in serum and liver of CTL and IR animals was measured using the colorimetric method (serum $n=8$ per group; liver $n=5$ per group). (B,C) Levels of transferrin receptor (Trf-R) and ferritin were determined by ELISA. (serum Trf-R $n=3$ per group; liver and hippocampus $\operatorname{Trf}-\mathrm{R} n=5$ per group; serum ferritin $n=5$ per group; liver, striatum (STR), prefrontal cortex (PFC), and hippocampus (HIP) ferritin $n=5$ per group). Each dot represents result of an animal and horizontal line represents median of the group. ${ }^{*} p<0.05$.

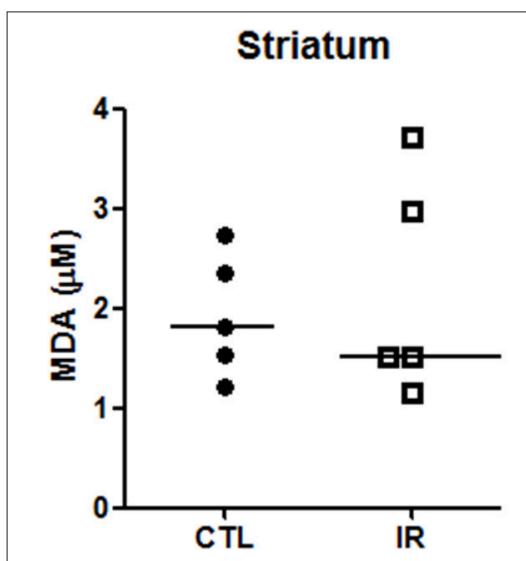

Prefrontal Cortex

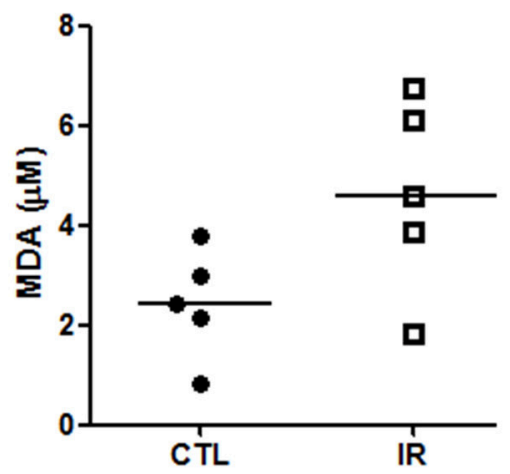

Hippocampus

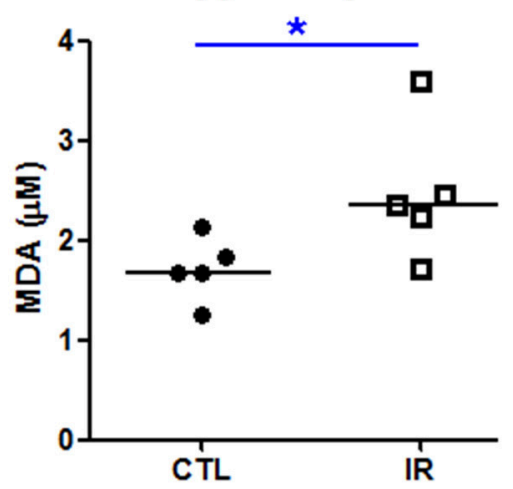

FIGURE 2 | Lipid peroxidation. The concentration of malondialdehyde (MDA), a product of lipid peroxidation, was measured in striatum, prefrontal cortex and hippocampus using thiobarbituric acid ( $n=5$ per group). Each dot represents result of an animal and horizontal line represents median of the group. ${ }^{\star} p<0.05$.

cortex, ferritin level was not altered (Figure 1C). Although we were not able to detect iron in brain tissues using the colorimetric assay, ferritin levels of each region indirectly indicate that the depletion of the brain iron pool is controlled in a region-specific manner.
To verify the effects of this heterogeneous iron depletion on redox balance, we evaluated the extent of lipid peroxidation in each region using thiobarbituric acid. As shown in Figure 2, only hippocampus of IR group, which had lower levels of ferritin, presented higher degree of lipid peroxidation compared to CTL 
group (Figure 2). Significant alterations were not observed in other regions.

\section{Effects of Dietary Iron Restriction on Dopamine Metabolism}

Effects of iron restriction on dopamine metabolism have been extensively investigated in human and in animal models, especially in the nigrostriatal pathway (Youdim et al., 1989;
Bianco et al., 2008; Unger et al., 2014). To confirm and complement these previous observations, we measured total dopamine levels in three brain areas.

In striatum, dopamine levels were not altered by iron restricted diet (Figure 3A). However, the levels of 3,4Dihydroxyphenylacetic acid (DOPAC) and homovanillic acid (HVA) were reduced in IR group compared to CTL group (Figures 3B,C). This reduction was neither due to the altered

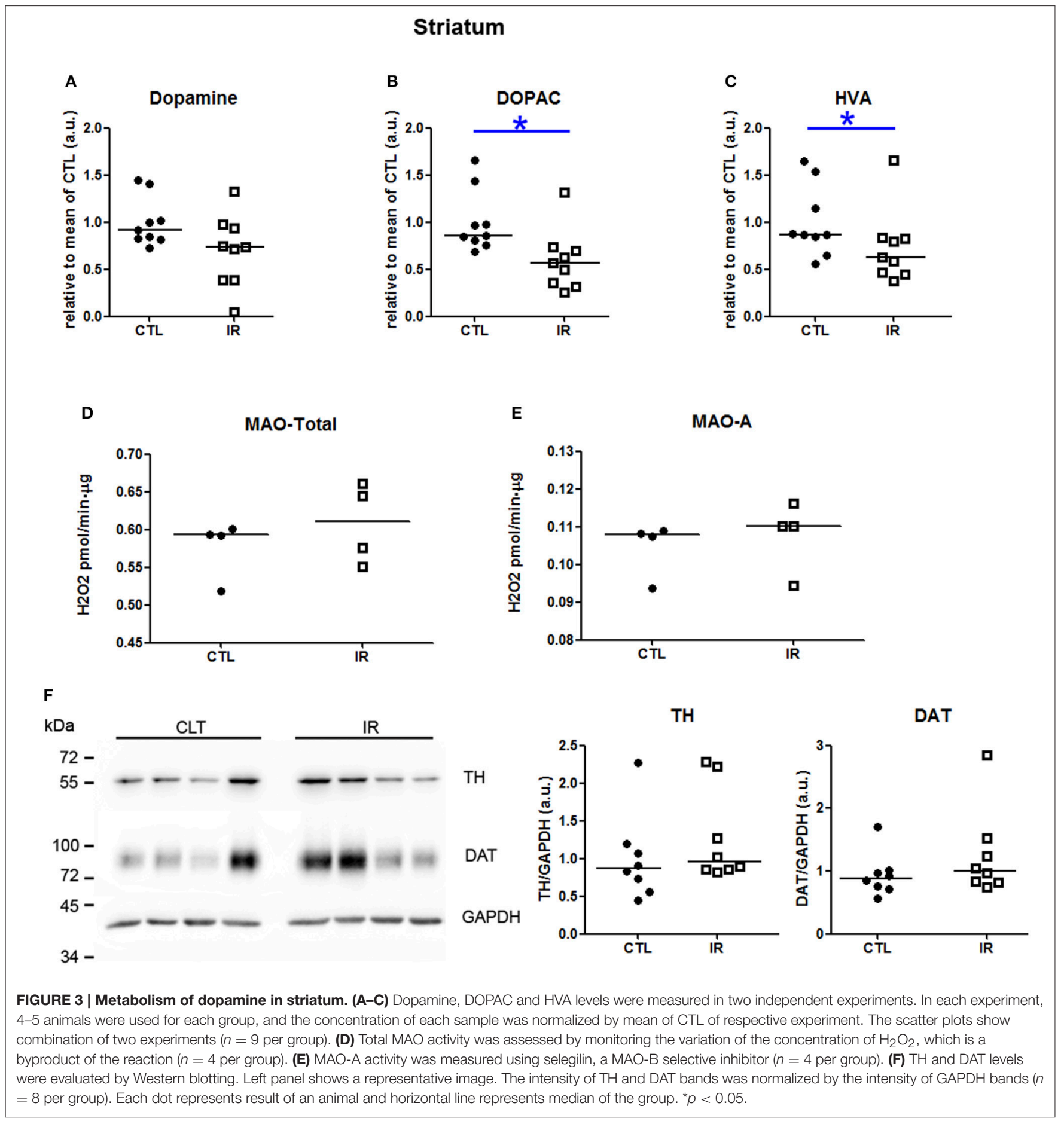


activity of monoamine oxidase (MAO) (Figures 3D,E) nor due to the expression level of tyrosine hydroxylase (TH) (Figure 3F). Iron restriction also did not alter the level of DAT (Figure 3F). These results were somewhat expected based on the previous findings, except DAT expression which was expected to be lower in IR group (Bianco et al., 2008; Unger et al., 2014). This subtle difference might have occurred due to the distinct age and species of animals used in each study. In previous studies, dorsal striatum of 65 days old rats was used, while in our study, whole striatum of 4 month old mice was used. Similarity of the results observed in two distinct animal models indicates that the reduction of dopamine metabolites in iron deficient animals is a robust phenomenon.

In prefrontal cortex, iron restriction promoted an increase of HVA levels in IR group compared to CTL group (Figure 4C). Dopamine and DOPAC levels did not differ significantly between the groups (Figures 4A,B). The increase of HVA might be caused due to the increased MAO-A activity (Figure 4E). Total MAO activity was not altered by iron restriction (Figure 4D). Neither TH nor DAT were affected (Figure 4F).

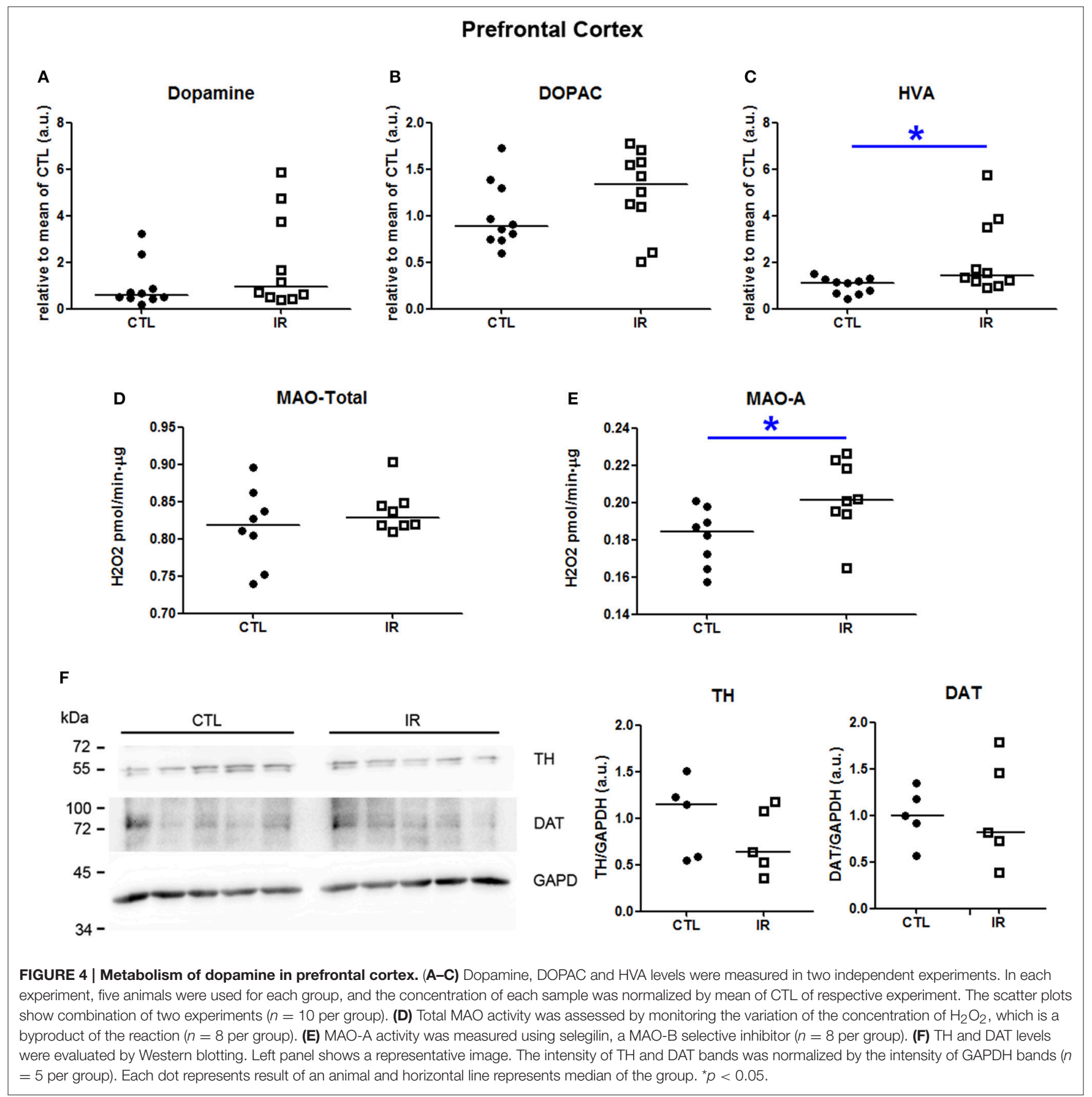


In hippocampus, levels of dopamine and its metabolites were not altered with iron restricted diet (Figure 5). Moreover, we were not able to detect DAT or $\mathrm{TH}$ in a reliable manner. Hippocampus receives only a small portion of dopaminergic innervation from ventral tegmental area (VTA) (Gasbarri et al., 1994). Thus, it is expected that the detection of $\mathrm{TH}$ or DAT in hippocampus would be more difficult than in other regions.

\section{Effects of Dietary Iron Restriction on PrPC and $\alpha$-Synuclein}

Since both $\operatorname{PrP}^{\mathrm{C}}$ and $\alpha$-synuclein play roles in iron and dopamine metabolism (Wong and Duce, 2014; Haldar et al., 2015; da Luz et al., 2015, 2016; Benskey et al., 2016), we investigated how dietary iron restriction affected the expression level of these proteins in each region by Western Blots. For the quantification of $\mathrm{PrP}^{\mathrm{C}}$, we measured the intensity of three bands that correspond to di-, mono-, and unglycosylated forms. The band intensity of protein of interest was normalized by GAPDH given that the alteration of GAPDH expression in IR group was not noticeable. To enhance the reliability of the results, each independent biological sample was assayed at least in duplicate and the mean of replicates was used for statistical analysis and presented in the graphs.

In striatum, $\mathrm{PrP}^{\mathrm{C}}$ levels were increased in IR group compared to CTL group (Figure 6A). In other regions, iron restriction did not produce significant effects on $\mathrm{PrP}^{\mathrm{C}}$ levels (Figures 6B,C). With regard to $\alpha$-synuclein, none of the regions presented significant alteration in IR group (Figures 7A-C).

Protein aggregation is a concentration-dependent process. As dietary iron restriction increased $\mathrm{PrP}^{\mathrm{C}}$ levels in the striatum, we verified whether this increase affected its solubility. Insoluble protein oligomers (pellet) were recovered by ultracentrifugation, and $\mathrm{PrP}^{\mathrm{C}}$ of each fraction was detected by Western blot. To improve the signal detection in pellet fractions, 20 -fold higher equivalent amounts of pellet were loaded into gel compared to supernatants. The striatum of IR group presented higher amount of $\mathrm{PrP}^{\mathrm{C}}$ in the supernatant compared to CTL group, but both groups presented similar scarce amount of $\mathrm{PrP}^{\mathrm{C}}$ in pellet fraction
(Figure 8A), indicating that enhanced expression level of $\mathrm{PrP}^{\mathrm{C}}$ did not culminate into aggregation.

Hippocampus is one of the brain regions that express highest level of $\operatorname{PrP}^{\mathrm{C}}$ (Tanji et al., 1995; Salès et al., 2002). Moreover, $\operatorname{PrP}^{\mathrm{C}}$ is known to play antioxidant roles with the ability to directly react with ROS, producing insoluble oligomers (Bertuchi et al., 2012; da Luz et al., 2015). Since we observed higher levels of lipid peroxidation in the hippocampus of IR group, we verified whether dietary iron restriction was also capable of changing the $\mathrm{PrP}^{\mathrm{C}}$ solubility. As shown in Figure 8B, both groups presented similar amount of $\mathrm{PrP}^{\mathrm{C}}$ in pellet and supernatant. Nevertheless, relatively weak GAPDH signal in pellets reinforces that $\mathrm{PrP}^{\mathrm{C}}$ is more prone to aggregate than GAPDH.

Altogether, these findings demonstrate that chronic insufficiency of dietary iron supply evokes distinct responses in striatum, prefrontal cortex and hippocampus with respect to iron and dopamine metabolism and proteostasis.

\section{DISCUSSION}

Conformational changes in proteins and deposition of their aggregates are common hallmarks of several neurodegenerative diseases. Thus, identification of conditions that lead to protein aggregation is important not only for elucidation of mechanism of pathogenesis, but also to establish diverse strategies of prevention and treatment. Many studies have demonstrated a close relationship between iron and dopamine metabolism and neurodegenerative diseases (Belaidi and Bush, 2015; Hare and Double, 2016). In this study, we aimed to disturb dopamine metabolism by restricting dietary iron and investigate how altered iron and dopamine metabolism affect proteostasis of $\mathrm{PrP}^{\mathrm{C}}$ and $\alpha$-synuclein.

Previous studies have demonstrated that 30 or less days of dietary iron restriction were sufficient to mimic iron deficiency in animal models with reduced iron and ferritin levels in liver and serum (Youdim et al., 1989; Kamei et al., 2013). Indeed, we observed reduced iron and ferritin levels in liver of IR group as expected. However, we did not observe alterations in serum iron levels although serum ferritin level was reduced. This lack of

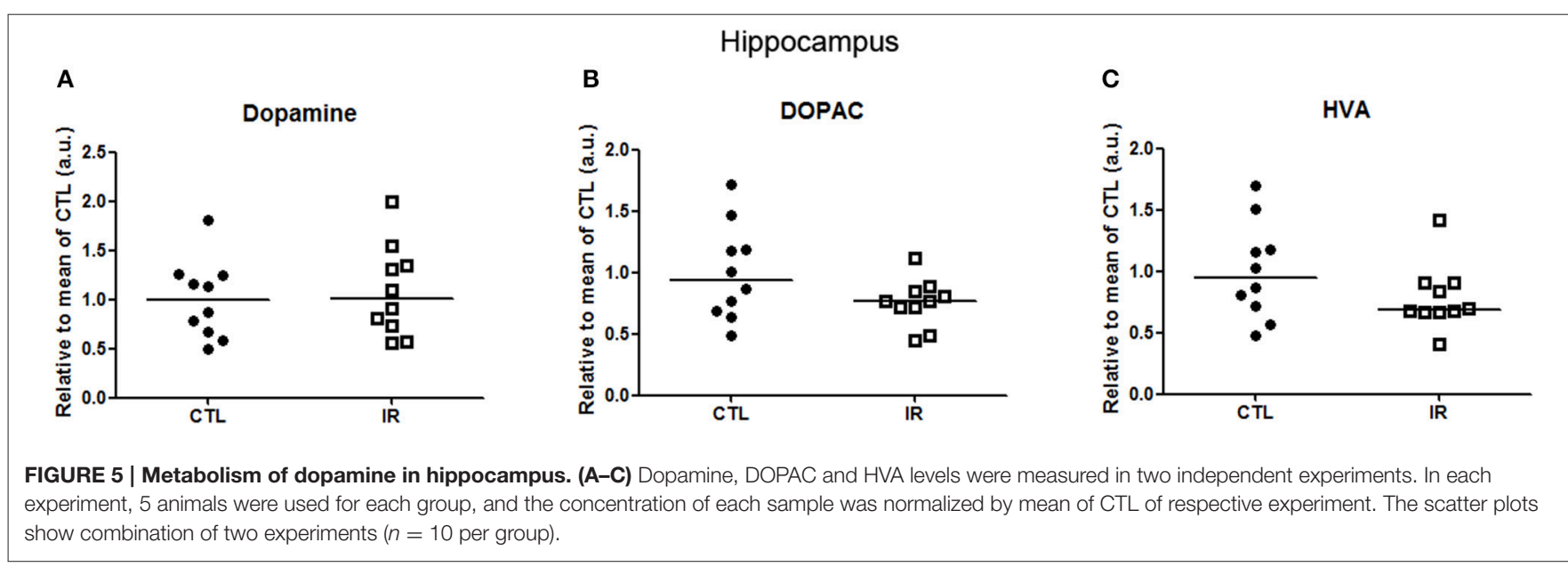




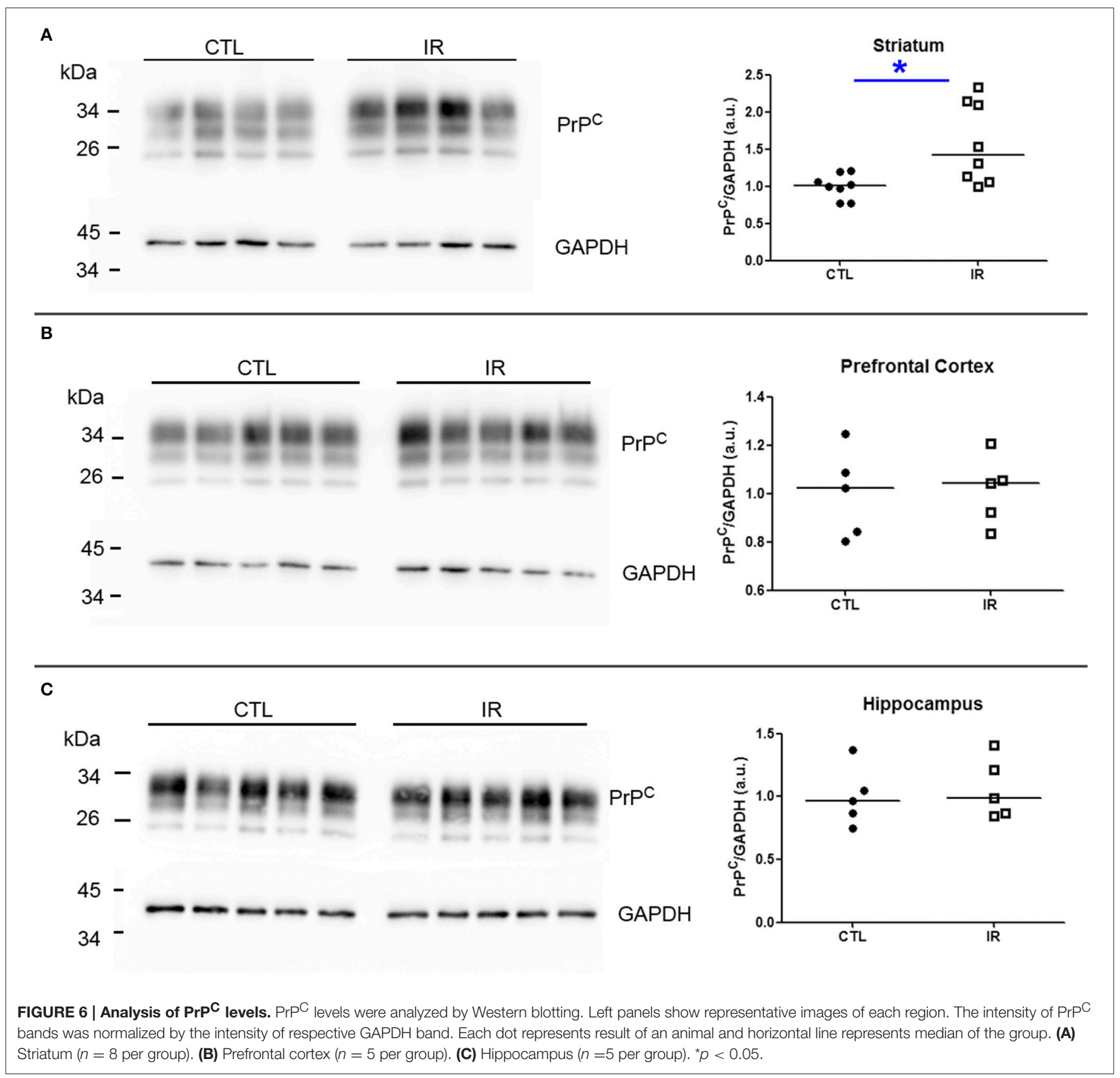

correlation between total iron pool and ferritin levels in serum can be explained by abundant presence of other iron binding proteins such as transferrin, albumin and free hemoglobin. Indeed, red blood cells are considered one of largest iron pools. Considering that half-life time of red blood cells or hemoglobin of mice is more than 30 days and most of iron derived from red blood cells are recycled and not excreted (Vanputten, 1958; De Domenico et al., 2008; Muñoz et al., 2009), it is reasonable to expect that 30 days of nutritional iron restriction do not significantly deplete the iron pool in blood. In addition, lack of a significant increase of transferrin receptor in all tissues evaluated in this study also indicates that our experimental condition was not sufficient to fully exhaust iron stores (Skikne et al., 1990; Cook, 2005). In younger animals, shorter period of iron restriction can robustly increase the expression of transferrin receptor (Moos et al., 1998), suggesting that age is an important factor that influence the responses to dietary iron restriction.

In addition to partial depletion of peripheral iron pools, we also observed reduced ferritin levels in hippocampus, indicating that brain iron metabolism was also affected by our experimental protocol. Concomitant with ferritin reduction, higher degree of lipid peroxidation was observed in the hippocampus of iron restricted animals. Iron deficiency is known to reduce 


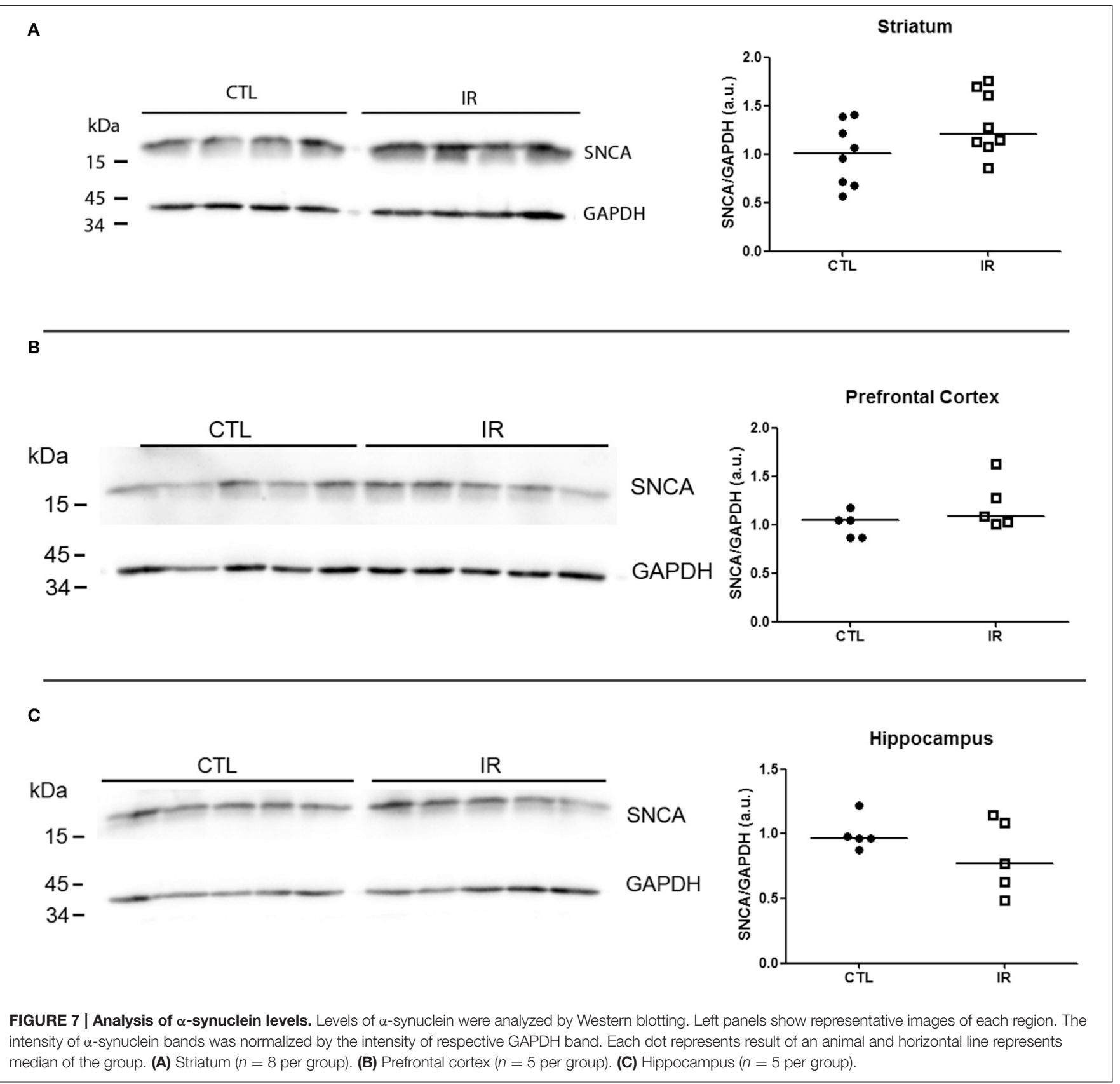

cytochrome $\mathrm{C}$ activity and energy metabolism, leading to increased production of reactive oxygen species (de Deungria et al., 2000; Carlson et al., 2009; Srinivasan and Avadhani, 2012). Moreover, iron deficiency can reduce mTOR activity in hippocampus via REDD1, a signaling molecule that can be activated by reactive oxygen species (Ohyashiki et al., 2009; Waibel et al., 2009). Thus, our observations appear to corroborate these previous findings that show increased oxidative stress in hippocampus under iron deficient condition.

Intriguingly, ferritin level was increased in the striatum of iron-deprived animals. This result was somewhat similar to the results reported in previous study, which showed that the treatment of younger rats with iron deficient diet reduced the iron level in hippocampus, but not in striatum (Erikson et al., 1997). Iron distribution in the normal brain is known to be heterogeneous (Hill and Switzer, 1984; Rouault, 2013), and striatum is one of the regions that have higher iron levels in the adult brain and is one of the sites where iron accumulates during normal aging (Martin et al., 1998). Altogether, these findings suggest that each brain region has distinct iron requirements, and under iron deficient condition, each region might develop distinct capacity of iron storage by altering the ferritin expression level. Nonetheless, abnormal ferritin accumulation in the striatum has been referred to as an early 


\section{A Striatum}
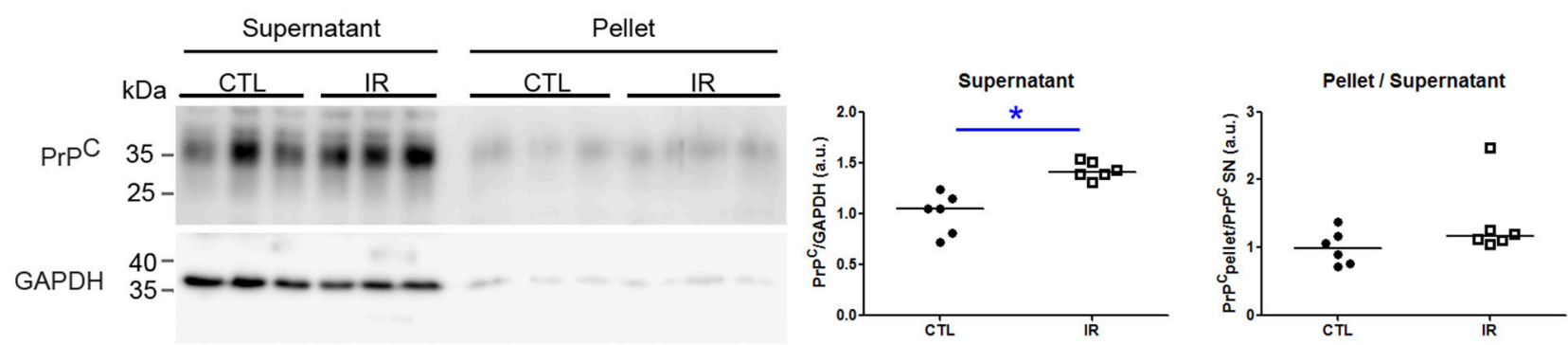

\section{B Hippocampus}
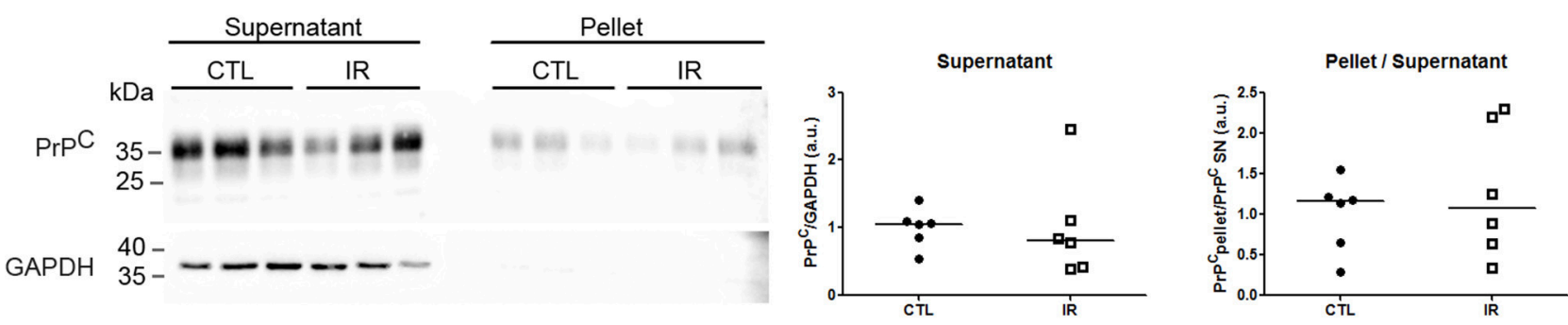

FIGURE 8 | Analysis of PrPC solubility. Soluble (supernatant) and insoluble (pellet) fractions were separated by ultracentrifugation and PrPC and GAPDH were detected by Western blotting. Left panels show representative images of each region. To estimate relative amount of PrPC in supernatant, PrPC band intensity was divided by respective GAPDH signals. The ratio of insoluble PrPC was calculated by dividing the intensity of pellet signals by respective supernatant signals. All results were normalized by mean of CTL group. Each dot represents result of an animal and horizontal line represents median of the group. (A) Striatum ( $n=6$ per group) (B) Hippocampus ( $n=6$ per group). ${ }^{*} p<0.05$.

event in neurological motor dysfunction such as Parkinsonism and Huntington disease (Vidal et al., 2004; Oakley et al., 2007; Simmons et al., 2007). Although underlying mechanisms needs to be further investigated, our data show that chronic nutritional iron deficiency can trigger molecular alterations observed in early stage of neurological disorders that involve degeneration of dopaminergic neurons.

Similar to ferritin levels that varied in a region-specific manner, dopamine metabolism of each region also generated distinct outcomes in animals subjected to dietary iron restriction. In hippocampus, which receives relatively small portion of dopaminergic innervation from VTA, iron restriction did not cause any significant alterations. In prefrontal cortex, which receives innervation from same region, dopamine or DOPAC levels were also not altered in IR group. However, HVA levels were increased probably due to the increased MAO-A activity. Previous studies have demonstrated that iron chelators can reduce the MAO activity, suggesting that iron bioavailability can affect the MAO activity (Zheng et al., 2005; Gal et al., 2006). The underlying mechanism of induction of MAO-A activity in IR group is still unclear, but these results can help to explain the symptoms of depression reported in iron-deficient population (Corwin et al., 2003), since increased MAO-A activity has been linked to mood disorders (Meyer et al., 2009; Sacher et al., 2015; Kolla et al., 2016).

Reduced levels of dopamine and/or its metabolites in striatum of IR group were rather expected based on previous observations
(Unger et al., 2014; Matak et al., 2016). It is tempting to speculate that this reduction occurred due to the compromised dopamine synthesis, since iron is a cofactor for tyrosine hydroxylase, an enzyme that catalyzes limiting step of dopamine synthesis. On the other hand, iron deficiency is known to evoke abnormal signaling via D2 receptor (Youdim et al., 1989; Erikson et al., 2001; Matak et al., 2016). Activation of D2 auto receptors regulates dopamine release and TH activity (Ford, 2014). Thus, it is possible that abnormal D2 receptor signaling contributed to reduced levels of dopamine metabolites in striatum of iron deprived animals.

Since extensive studies have demonstrated the involvement of $\mathrm{PrP}^{\mathrm{C}}$ and $\alpha$-synuclein in dopamine and iron metabolism, we evaluated how these divergent outcomes of dietary iron restriction in each region affected the proteostasis of both proteins. Regarding the expression levels, only $\mathrm{PrP}^{\mathrm{C}}$ of the striatum was significantly increased after iron restriction. Previous studies have demonstrated that high concentration of dopamine can promote oxidation and oligomerization of $\mathrm{PrP}^{\mathrm{C}}$ (Shiraishi et al., 2005; da Luz et al., 2015). $\operatorname{PrP}^{\mathrm{C}}$ can also regulate dopamine metabolism by suppressing the TH expression (Beckman et al., 2015; da Luz et al., 2016). However, in this study, we observed that iron restriction reduced the levels of dopamine metabolites in the striatum, without affecting $\mathrm{TH}$ levels or $\mathrm{PrP}^{\mathrm{C}}$ solubility. Thus, increased $\mathrm{PrP}^{\mathrm{C}}$ levels observed in this region might not be related with dopamine metabolism. On the other hand, $\operatorname{PrP}^{\mathrm{C}}$ is known to play roles in iron uptake by acting 
as ferrireductase, and its expression appears to correlate with ferritin expression (Singh et al., 2013; Haldar et al., 2015; Tripathi et al., 2015). Thus, the increase of $\operatorname{PrP}^{C}$ in striatum of IR group is more likely related to iron recruitment into the striatum leading to the increased ferritin level. Moreover, the regulation of ferritin and $\mathrm{PrP}^{\mathrm{C}}$ expression might play important roles for intracellular iron buffering capacity since dietary iron restriction did not alter expression levels of $\alpha$-synuclein in any brain regions, despite previous report showing reduced translation of $\alpha$-synuclein upon iron chelation (Febbraro et al., 2012). These results also reinforce specificity of the iron restriction effects on proteins of distinct subcellular comportments.

Altogether, our results demonstrate that insufficient dietary iron supply can establish molecular features that resemble several neurological disorders, such as abnormal ferritin accumulation in striatum observed in parkinsonian syndromes and Huntington disease (Vidal et al., 2004; Simmons et al., 2007), increased MAO-A activity in prefrontal cortex which is associated with depression (Meyer et al., 2009) and increased degree of lipid peroxidation in hippocampus that is related with most of conformational diseases (Sultana et al., 2013). By showing these molecular alterations, this study emphasizes the importance of adequate iron supplementation for brain health and prevention of neurological diseases. Moreover, these brain region-specific responses can be useful information to better understand the

\section{REFERENCES}

Asanuma, M., Miyazaki, I., and Ogawa, N. (2003). Dopamine- or L-DOPAinduced neurotoxicity: the role of dopamine quinone formation and tyrosinase in a model of Parkinson's disease. Neurotox. Res. 5, 165-176. doi: $10.1007 /$ bf03033137

Beard, J. L., Chen, Q., Connor, J., and Jones, B. C. (1994). Altered monamine metabolism in caudate-putamen of iron-deficient rats. Pharmacol. Biochem. Behav. 48, 621-624. doi: 10.1016/0091-3057(94)90323-9

Beckman, D., Santos, L. E., Americo, T. A., Ledo, J. H., de Mello, F. G., and Linden, R. (2015). Reply to altered monoaminergic systems and depressive-like behavior in congenic prion protein knock-out mice. J. Biol. Chem. 290, 26351. doi: 10.1074/jbc.L115.689232

Belaidi, A. A., and Bush, A. I. (2015). Iron neurochemistry in Alzheimer's disease and Parkinson's disease: targets for therapeutics. J. Neurochem. 139, 179-197. doi: $10.1111 /$ jnc. 13425

Benskey, M. J., Perez, R. G., and Manfredsson, F. P. (2016). The contribution of alpha synuclein to neuronal survival and function-Implications for Parkinson's disease. J. Neurochem. 137, 331-359. doi: 10.1111/jnc.13570

Bertuchi, F. R., Bourgeon, D. M. G., Landemberger, M. C., Martins, V. R., and Cerchiaro, G. (2012). PrPC displays an essential protective role from oxidative stress in an astrocyte cell line derived from PrPC knockout mice. Biochem. Biophys. Res. Commun. 418, 27-32. doi: 10.1016/j.bbrc.2011.12.098

Bianco, L. E., Wiesinger, J., Earley, C. J., Jones, B. C., and Beard, J. L. (2008). Iron deficiency alters dopamine uptake and response to LDOPA injection in Sprague-Dawley rats. J. Neurochem. 106, 205-215. doi: 10.1111/j.1471-4159.2008.05358.x

Bissonette, G. B., and Roesch, M. R. (2016). Development and function of the midbrain dopamine system: what we know and what we need to. Genes. Brain. Behav. 15, 62-73. doi: 10.1111/gbb.12257

Bradbury, M. W. (1997). Transport of iron in the blood-brain-cerebrospinal fluid system. J. Neurochem. 69, 443-454. doi: 10.1046/j.1471-4159.1997.69020443.x

Carlson, E. S., Tkac, I., Magid, R., O’Connor, M. B., Andrews, N. C., Schallert, T., et al. (2009). Iron is essential for neuron development and memory diversity of the disorders that can be generated by altered iron metabolism.

\section{AUTHOR CONTRIBUTIONS}

JP conducted all experiments. Md assisted in animal handling and western blotting. HA and SG assisted in animal handling and sample collection. VM helped with the study design and interpretation of data, and revised the manuscript. KL conceived and supervised the study, and wrote the manuscript. All authors contributed to final version of the manuscript.

\section{FUNDING}

This study was supported by grants from FAPESP (Fundação de Amparo à Pesquisa do Estado de São Paulo: 2016/04297-6), $\mathrm{CNPq}$ (Conselho Nacional de Desenvolvimento Científico e Tecnológico: 467566/2014-3), CAPES (Coordenação de Aperfeiçoamento de pessoal de Nível Superior) and EMU (programa de equipamentos multiusuários).

\section{ACKNOWLEDGMENTS}

We thank Dr. Mirian Akemi Furuie Hayashi from UNIFESP for making HPLC-ECD system available for monoamine analysis.

function in mouse hippocampus. J. Nutr. 139, 672-679. doi: 10.3945/jn.108. 096354

Cook, J. D. (2005). Diagnosis and management of iron-deficiency anaemia. Best Pract. Res. Clin. Haematol. 18, 319-332. doi: 10.1016/j.beha.2004.08.022

Corwin, E. J., Murray-Kolb, L. E., and Beard, J. L. (2003). Low hemoglobin level is a risk factor for postpartum depression. J. Nutr. 133, 4139-4142.

da Luz, M. H. M., Glezer, I., Xavier, A. M., da Silva, M. A. P., Pino, J. M. V., Zamith, T. P., et al. (2016). Expression of Tyrosine Hydroxylase is Negatively Regulated Via Prion Protein. Neurochem. Res. 41, 1691-1699. doi: 10.1007/s11064-016-1885-1

da Luz, M. H. M., Peres, I. T., Santos, T. G., Martins, V. R., Icimoto, M. Y., and Lee, K. S. (2015). Dopamine induces the accumulation of insoluble prion protein and affects autophagic flux. Front. Cell. Neurosci. 9:12. doi: 10.3389/fncel.2015.00012

Das, D., Luo, X., Singh, A., Gu, Y., Ghosh, S., Mukhopadhyay, C. K., et al. (2010). Paradoxical role of prion protein aggregates in redox-iron induced toxicity. PLoS ONE 5:e11420. doi: 10.1371/journal.pone.0011420

de Deungria, M., Rao, R., Wobken, J. D., Luciana, M., Nelson, C. A., and Georgieff, M. K. (2000). Perinatal iron deficiency decreases cytochrome c oxidase (CytOx) activity in selected regions of neonatal rat brain. Pediatr. Res. 48, 169-176. doi: 10.1203/00006450-200008000-00009

De Domenico, I., McVey Ward, D., and Kaplan, J. (2008). Regulation of iron acquisition and storage: consequences for iron-linked disorders. Nat. Rev. Mol. Cell Biol. 9, 72-81. doi: 10.1038/nrm2295

Erikson, K. M., Jones, B. C., Hess, E. J., Zhang, Q., and Beard, J. L. (2001). Iron deficiency decreases dopamine D1 and D2 receptors in rat brain. Pharmacol. Biochem. Behav. 69, 409-418. doi: 10.1016/S0091-3057(01) 00563-9

Erikson, K. M., Pinero, D. J., Connor, J. R., and Beard, J. L. (1997). Regional brain iron, ferritin and transferrin concentrations during iron deficiency and iron repletion in developing rats. J. Nutr. 127, 2030-2038.

Febbraro, F., Giorgi, M., Caldarola, S., Loreni, F., and Romero-Ramos, M. (2012). $\alpha$-Synuclein expression is modulated at the translational level by iron. Neuroreport 23, 576-580. doi: 10.1097/WNR.0b013e328354a1f0 
Ford, C. P. (2014). The role of D2-autoreceptors in regulating dopamine neuron activity and transmission. Neuroscience 282, 13-22. doi: 10.1016/j.neuroscience.2014.01.025

Gal, S., Fridkin, M., Amit, T., Zheng, H., and Youdim, M. B. H. (2006). $\mathrm{M} 30$, a novel multifunctional neuroprotective drug with potent iron chelating and brain selective monoamine oxidase-ab inhibitory activity for Parkinson's disease. J. Neural Transm. Suppl. 70, 447-456. doi: 10.1007/978-3-211-45295-0_68

Gasbarri, A., Verney, C., Innocenzi, R., Campana, E., and Pacitti, C. (1994). Mesolimbic dopaminergic neurons innervating the hippocampal formation in the rat: a combined retrograde tracing and immunohistochemical study. Brain Res. 668, 71-79.

Golts, N., Snyder, H., Frasier, M., Theisler, C., Choi, P., and Wolozin, B. (2002). Magnesium inhibits spontaneous and iron-induced aggregation of alphasynuclein. J. Biol. Chem. 277, 16116-16123. doi: 10.1074/jbc.M107866200

Gupta, S. (2016). Brain food: clever eating. Nature 531, S12-S3. doi: $10.1038 / 531$ S12a

Haldar, S., Tripathi, A., Qian, J., Beserra, A., Suda, S., McElwee, M., et al. (2015). Prion protein promotes kidney iron uptake via its ferrireductase activity. J. Biol. Chem. 290, 5512-5522. doi: 10.1074/jbc.M114.607507

Hare, D. J., and Double, K. L. (2016). Iron and dopamine: a toxic couple. Brain 139(Pt 4), 1026-1035. doi: 10.1093/brain/aww,022

Hill, J. M., and Switzer, R. C. (1984). The regional distribution and cellular localization of iron in the rat brain. Neuroscience 11, 595-603. doi: 10.1016/0306-4522(84)90046-0

Kamei, A., Watanabe, Y., Kondo, K., Okada, S., Shinozaki, F., Ishijima, T., et al. (2013). Influence of a short-term iron-deficient diet on hepatic gene expression profiles in rats. PLoS ONE 8:e65732. doi: 10.1371/journal.pone.0065732

Kolla, N. J., Chiuccariello, L., Wilson, A. A., Houle, S., Links, P., Bagby, R. M., et al. (2016). Elevated monoamine oxidase-a distribution volume in borderline personality disorder is associated with severity across mood symptoms, suicidality, and cognition. Biol. Psychiatry 79, 117-126. doi: 10.1016/j.biopsych.2014.11.024

Liu, B., Moloney, A., Meehan, S., Morris, K., Thomas, S. E., Serpell, L. C., et al. (2011). Iron promotes the toxicity of amyloid $\beta$ peptide by impeding its ordered aggregation. J. Biol. Chem. 286, 4248-4256. doi: 10.1074/jbc.M110.158980

Lotharius, J., and Brundin, P. (2002). Pathogenesis of Parkinson's disease: dopamine, vesicles and alpha-synuclein. Nat. Rev. Neurosci. 3, 932-942. doi: $10.1038 / \mathrm{nrn} 983$

Martin, W. R., Ye, F. Q., and Allen, P. S. (1998). Increasing striatal iron content associated with normal aging. Mov. Disord. 13, 281-286. doi: $10.1002 / \mathrm{mds} .870130214$

Masini, A., Trenti, T., Caramazza, I., Predieri, G., Gallesi, D., and Ceccarelli, D. (1994). Dietary iron deficiency in the rat. II. Recovery from energy metabolism derangement of the hepatic tissue by iron therapy. Biochim. Biophys. Acta 1188, 53-57. doi: 10.1016/0005-2728(94)90021-3

Matak, P., Matak, A., Moustafa, S., Aryal, D. K., Benner, E. J., Wetsel, W. C., et al. (2016). Disrupted iron homeostasis causes dopaminergic neurodegeneration in mice. Proc. Natl. Acad. Sci. U.S.A. 113, 1-8. doi: 10.1073/pnas.1519473113

Meyer, J. H., Wilson, A. A., Sagrati, S., Miler, L., Rusjan, P., Bloomfield, P. M., et al. (2009). Brain monoamine oxidase A binding in major depressive disorder: relationship to selective serotonin reuptake inhibitor treatment, recovery, and recurrence. Arch. Gen. Psychiatry 66, 1304-1312. doi: 10.1001/archgenpsychiatry.2009.156

Moos, T., Oates, P. S., and Morgan, E. H. (1998). Expression of the neuronal transferrin receptor is age dependent and susceptible to iron deficiency. J. Comp. Neurol. 398, 420-430. doi: 10.1002/(SICI)1096-9861(19980831)398:3< 420::AID-CNE8 > 3.0.CO;2-1

Muñoz, M., Villar, I., and García-Erce, J. A. (2009). An update on iron physiology. World J. Gastroenterol. 15, 4617-4626. doi: 10.3748/wjg.15.4617

Oakley, A. E., Collingwood, J. F., Dobson, J., Love, G., Perrott, H. R., Edwardson, J. A., et al. (2007). Individual dopaminergic neurons show raised iron levels in Parkinson disease. Neurology 68, 1820-1825. doi: 10.1212/01.wnl.0000262033.01945.9a

Ohyashiki, J. H., Kobayashi, C., Hamamura, R., Okabe, S., Tauchi, T., and Ohyashiki, K. (2009). The oral iron chelator deferasirox represses signaling through the mTOR in myeloid leukemia cells by enhancing expression of REDD1. Cancer Sci. 100, 970-977. doi: 10.1111/j.1349-7006.2009.01131.x
Radlowski, E. C., and Johnson, R. W. (2013). Perinatal iron deficiency and neurocognitive development. Front. Hum. Neurosci. 7:585. doi: 10.3389/fnhum.2013.00585

Rouault, T. A. (2013). Iron metabolism in the CNS: implications for neurodegenerative diseases. Nat. Rev. Neurosci. 14, 551-564. doi: $10.1038 / \mathrm{nrn} 3453$

Russo, S. J., and Nestler, E. J. (2013). The brain reward circuitry in mood disorders. Nat. Rev. Neurosci. 14, 609-625. doi: 10.1038/nrn3381

Sacher, J., Rekkas, P. V., Wilson, A. A., Houle, S., Romano, L., Hamidi, J., et al. (2015). Relationship of monoamine oxidase-A distribution volume to postpartum depression and postpartum crying. Neuropsychopharmacology 40, 429-435. doi: 10.1038/npp.2014.190

Salès, N., Hässig, R., Rodolfo, K., Di Giamberardino, L., Traiffort, E., Ruat, M., et al. (2002). Developmental expression of the cellular prion protein in elongating axons. Eur. J. Neurosci. 15, 1163-1177. doi: 10.1046/j.1460-9568.2002.01953.x

Scott, S. P., and Murray-Kolb, L. E. (2016). Iron status is associated with performance on executive functioning tasks in nonanemic young women. J. Nutr. 146, 30-37. doi: 10.3945/jn.115.223586

Shiraishi, N., Inai, Y., Bi, W., and Nishikimi, M. (2005). Fragmentation and dimerization of copper-loaded prion protein by copper-catalysed oxidation. Biochem. J. 387, 247-255. doi: 10.1042/BJ20041561

Simmons, D. A., Casale, M., Alcon, B., Pham, N., Narayan, N., and Lynch, G. (2007). Ferritin accumulation in dystrophic microglia is an early event in the development of Huntington's disease. Glia 55, 1074-1084. doi: $10.1002 /$ glia.20526

Singh, A., Haldar, S., Horback, K., Tom, C., Zhou, L., Meyerson, H., et al. (2013). Prion protein regulates iron transport by functioning as a ferrireductase. $J$. Alzheimers. Dis. 35, 541-552. doi: 10.3233/JAD-130218

Skikne, B. S., Flowers, C. H., and Cook, J. D. (1990). Serum transferrin receptor: a quantitative measure of tissue iron deficiency. Blood 75, 1870-1876.

Srinivasan, S., and Avadhani, N. G. (2012). Cytochrome c oxidase dysfunction in oxidative stress. Free Radic. Biol. Med. 53, 1252-1263. doi: 10.1016/j.freeradbiomed.2012.07.021

Sultana, R., Perluigi, M., and Allan Butterfield, D. (2013). Lipid peroxidation triggers neurodegeneration: a redox proteomics view into the Alzheimer disease brain. Free Radic. Biol. Med. 62, 157-169. doi: 10.1016/j.freeradbiomed.2012.09.027

Tanji, K., Saeki, K., Matsumoto, Y., Takeda, M., Hirasawa, K., Doi, K., et al. (1995). Analysis of PrPc mRNA by in situ hybridization in brain, placenta, uterus and testis of rats. Intervirology 38, 309-315. doi: 10.1159/000150457

Tripathi, A. K., Haldar, S., Qian, J., Beserra, A., Suda, S., Singh, A., et al. (2015). Prion protein functions as a ferrireductase partner for ZIP14 and DMT1. Free Radic. Biol. Med. 84, 322-330. doi: 10.1016/j.freeradbiomed.2015.03.037

Unger, E. L., Bianco, L. E., Jones, B. C., Allen, R. P., and Earley, C. J. (2014). Low brain iron effects and reversibility on striatal dopamine dynamics. Exp. Neurol. 261, 462-468. doi: 10.1016/j.expneurol.2014.06.023

Vanputten, , L. M. (1958). The life span of red cells in the rat and the mouse as determined by labeling with DFP32 in vivo. Blood 13, 789-794.

Vidal, R., Ghetti, B., Takao, M., Brefel-Courbon, C., Uro-Coste, E., Glazier, B. S., et al. (2004). Intracellular ferritin accumulation in neural and extraneural tissue characterizes a neurodegenerative disease associated with a mutation in the ferritin light polypeptide gene. J. Neuropathol. Exp. Neurol. 63, 363-380. doi: $10.1093 /$ jnen/63.4.363

Waibel, B. H., Schlitzkus, L. L., Newell, M. A., Durham, C. A., Sagraves, S. G., and Rotondo, M. F. (2009). Impact of hypothermia (below 36 degrees C) in the rural trauma patient. J. Am. Coll. Surg. 209, 580-588. doi: 10.1016/j.jamcollsurg.2009.07.021

Walter, P. B., Knutson, M. D., Paler-Martinez, A., Lee, S., Xu, Y., Viteri, F. E., et al. (2002). Iron deficiency and iron excess damage mitochondria and mitochondrial DNA in rats. Proc. Natl. Acad. Sci. U.S.A. 99, 2264-2269. doi: $10.1073 /$ pnas. 261708798

Wong, B. X., and Duce, J. A. (2014). The iron regulatory capability of the major protein participants in prevalent neurodegenerative disorders. Front. Pharmacol. 5:81. doi: 10.3389/fphar.2014.00081

Yamakawa, K., Izumi, Y., Takeuchi, H., Yamamoto, N., Kume, T., Akaike, A., et al. (2010). Dopamine facilitates alpha-synuclein oligomerization in human neuroblastoma SH-SY5Y cells. Biochem. Biophys. Res. Commun. 391, 129-134. doi: 10.1016/j.bbrc.2009.11.015 
Yetnikoff, L., Lavezzi, H. N., Reichard, R. A., and Zahm, D. S. (2014). An update on the connections of the ventral mesencephalic dopaminergic complex. Neuroscience 282, 23-48. doi: 10.1016/j.neuroscience.2014. 04.010

Youdim, M. B., Ben-Shachar, D., and Yehuda, S. (1989). Putative biological mechanisms of the effect of iron deficiency on brain biochemistry and behavior. Am. J. Clin. Nutr. 50, 607-615, discussion: 615-617.

Zecca, L., Youdim, M. B. H., Riederer, P., Connor, J. R., and Crichton, R. R. (2004). Iron, brain ageing and neurodegenerative disorders. Nat. Rev. Neurosci. 5, 863-873. doi: 10.1038/nrn1537

Zheng, H., Gal, S., Weiner, L. M., Bar-Am, O., Warshawsky, A., Fridkin, M., et al. (2005). Novel multifunctional neuroprotective iron chelatormonoamine oxidase inhibitor drugs for neurodegenerative diseases: in vitro studies on antioxidant activity, prevention of lipid peroxide formation and monoamine oxidase inhibition. J. Neurochem. 95, 68-78. doi: 10.1111/j.1471-4159.2005.03340.x

Conflict of Interest Statement: The authors declare that the research was conducted in the absence of any commercial or financial relationships that could be construed as a potential conflict of interest.

Copyright (C) 2017 Pino, da Luz, Antunes, Giampá, Martins and Lee. This is an open-access article distributed under the terms of the Creative Commons Attribution License (CC BY). The use, distribution or reproduction in other forums is permitted, provided the original author(s) or licensor are credited and that the original publication in this journal is cited, in accordance with accepted academic practice. No use, distribution or reproduction is permitted which does not comply with these terms. 